direction is trying to the observer, and should for that reason be avoided. Translucent test-charts are not recommended for use in a dark room. The choice should be in favour of surroundings of a subdued hue, if coloured at all. It is added that "the chart and the patient are to be so arranged that no light-source, window, or other spot of high brightness, such as wall or ceiling, used as secondary source in indirect and semi-indirect lighting, shall be visible to the patient while he is engaged in observing the test-chart."

As to perimetry, the peculiarities of the periphery of the retina led to consideration of the following factors:-(1) the rapid adaptation of the peripheral retina, owing to which a sensation rapidly loses its characteristic quality while the stimulus continues to act upon it ; (2) the fact that the peripheral retina is peculiarly subject to contrast, so that the same test surface gives different results according to the background upon which it is seen; and (3) the fact must not be overlooked that the results obtained are totally difterent with coloured test-spots of different sizes. Even the central retina fails to recognize colour when the coloured spot is small enough. The perimeters do not agree in so fundamental a dimension as the radius of the arc. Various makers put out test-colours of different hues and shades, which pass current under the same colour designation. The technique by which the colour is presented to the patient is extremely variable. The attention paid to the illumination of the test-spot seems wholly inadequate. When all is said and done, the fact remains : the patient is the one thing that cannot be standardized. It is difficult to ascertain whether the errors of perimetry are chiefly personal or chiefly technical, and the Committee recommends in pursuance of this idea that (1) "it be determined what the effect is of such difterences as obtain under the usual daylight illumination of the perimeter in the illumination of the test-spot in different parts of the visual field"; and (2) "samples of the colours be obtained from the various makers with a view to spectrophotometric or colorimetric examination and intercomparison, and possible adoption of certain ones as standard."

The preliminary report is signed by Drs. W. Zentmayer, G. S. Crampton, and H. M. Langdon.

In the final report we hope the Committee may succeed in fixing a definite standard.

\title{
American Board for Ophthalmic Examinations
}

We gather from the Annual Report of the American Board for Ophthalmic Examinations that examinations were held in December, 1916, at Memphis, and in June, 1917, in New York City, and that the total number of accepted applications was 117 . 
It has been decided in exceptional cases, where an applicant's public and definite record gives full guarantee of his fitness for ophthalmic practice, that the certificate of the Board should be granted without such an examination as would be necessary for those whose professional record had yet largely to be made. That the activities of the Board have already awakened an important interest in the subject of training for ophthalmic practice is shown by the number of letters, asking for details of the examinations or of the necessary course of study, received from individuals and from institutions.

During the term covered by the Report, Dr. John E. Weeks has succeeded Dr. William $\mathrm{H}$. Wilder as representing the American Ophthalmological Society, while Drs. E. C. Ellett and F. C. Todd, representatives of the Section on Ophthalmology of the American Medical Association and the American Academy of Ophthalmology and Oto-Laryngology, "were chosen to succeed themselves," their term of office having expired. The personnel of the Board during the year dealt with by the Report was as follows : Chairman, Edward Jackson; Vice-Chairman, Myles Standish ; Secretary, F. C. Todd; Committee on Preliminary Requirements, Myles Standish, William H. Wilder, and F. C. Todd; Committee on Examinations, Hiram Woods, Walter B. Lancaster, and Wendell Reber; Committee on Finance, Edward Jackson, E. C. Ellett, A. Duane.

An interesting question that had engaged the attention of the Board was the need of special examinations for applicants for Fellowship in the American College of Surgeons, who claimed eligibility upon the ground of being engaged in eye work, and the difficulties experienced by the College in giving such applicants proper examinations. The Board entered into negotiations with the authorities of the College, who agreed to leave the Board in control of all ophthalmic examinations, and to defray the expenses of the work. The urgency of the question may be gathered from the bald statement that there are now several hundred applicants awaiting examinations in ophthalmology to determine their fitness for Fellowship in the College.

\section{The new American Ophthalmic Journal}

As our readers are already aware, a new journal of ophthalmology has been projected in America for some little time. 'There exist many good reasons why such a venture should be undertaken at the present juncture, but into these we need not enter here. The name of the journal has not yet been announced, but it is to be published monthly, and the first number will appear in January, 